\title{
AVALIAÇÃO BALÍSTICA DE UM COMPÓSITO HÍBRIDO LAMINADO REFORÇADO COM MANTA DE CURAUÁ E TECIDO DE POLIARAMIDA*
}

\author{
Anderson Oliveira da Silva ${ }^{1}$ \\ Suzane de Sant' Ana Oliveira ${ }^{2}$ \\ Karollyne Gomes de Castro Monsores ${ }^{3}$ \\ Ricardo Pondé Weber ${ }^{4}$ \\ Sérgio Neves Monteiro ${ }^{5}$
}

\section{Resumo}

Blindagens balísticas são projetadas para resistir a uma determinada ameaça com a menor relação peso/resistência balística possível, isto é, oferecer a melhor resistência à penetração de projéteis e fragmentos provenientes de armas de fogo com menor peso. Os materiais compósitos são, atualmente, aqueles que possuem a maior probabilidade de obter estes requisitos, por possuírem flexibilidade de alcançarem o conjunto de propriedades mais apropriadas para cada nível de proteção e por serem mais leves. Os compósitos reforçados por tecidos de fibra sintética são atualmente os mais utilizados. Com o foco nos aspectos ambientais, este trabalho produziu e avaliou um compósito híbrido laminado de matriz polimérica reforçado por manta de curauá e tecido de poliamida aromática. O compósito foi avaliado segundo o tipo de falha ocorrida após o ensaio balístico, utilizando a análise por microscopia eletrônica de varredura (MEV), bem como, a análise visual. Por meio da análise dos resultados, foi possível observar que o processo de microdelaminações na interface matriz/tecidos, bem como as falhas intralamelares (trincas na matriz) proporcionaram uma maior dissipação da energia de impacto.

Palavras-chave: Compósito Híbrido; Manta de Curauá; Fratura; Blindagem.

\section{BALISTIC EVALUATION OF A HYBRID COMPOSITION REINFORCED WITH CURAUÁ BLANK AND POLYARAMID FABRIC}

\begin{abstract}
Ballistic shields are designed to withstand a given threat with the lowest weight / ballistic resistance ratio, that is, to provide the best resistance to penetration of projectiles and fragments from lightweight firearms. Composite materials are currently the ones most likely to obtain these requirements, because they have the flexibility to achieve the set of properties most appropriate for each level of protection and because they are lighter. Composites reinforced by synthetic fiber fabrics are currently the most widely used. With the focus on environmental aspects, this work produced and evaluated a laminated hybrid composite reinforced by curauá blanket and aromatic polyamide fabric. The composite was evaluated according to the type of failure that occurred after the ballistic test, using scanning electron microscopy (SEM) as well as visual analysis. The results showed that the microdelamination process at the interface matrix /fabrics, as well as the intralamellar faults (cracks in the matrix) provided a greater dissipation of the impact energy.
\end{abstract}

Keywords: Hybrid composite; Curauá Blanket; Fracture; Ballistic Armor.

Licenciado em Química, mestrando em Ciência dos Materiais, Seção de Engenharia Mecânica e de Materiais, Instituto Militar de Engenharia, Rio de Janeiro, RJ - Brasil.

2 Tecnóloga em Processos Metalúrgicos, doutoranda em Ciências dos Materiais, Seção de Engenharia Mecânica e de Materiais, Instituto Militar de Engenharia, Rio de Janeiro, RJ - Brasil.

3 Tecnóloga em Polímeros, doutoranda em Ciências dos Materiais, Instituto Militar de Engenharia, Rio de Janeiro, RJ - Brasil.

4 Engenheiro mecânico, Doutor em Ciências dos Materiais, Professor Pesquisador, Seção de Engenharia Mecânica e de Materiais, Instituto Militar de Engenharia, Rio de Janeiro, RJ - Brasil.

5 Engenheiro Metalurgista, Ph.D, Professor Titular, Seção de Engenharia Mecânica e de Materiais, Instituto Militar de Engenharia, Rio de Janeiro, RJ - Brasil. 


\section{INTRODUÇÃO}

Ao longo das últimas décadas, a necessidade de se obter blindagens com relação peso/proteção cada vez menor, desencadeou o desenvolvimento de novos materiais leves e com elevado desempenho mecânico e balístico. Por esse motivo, os requisitos exigidos para esta classe de novos materiais são tão grandes e diversos, que um único material não consegue satisfazê-los [1].

Este sinergismo, fez com que os materiais compósitos se tornassem grandes precursores na produção de vários sistemas de blindagens, principalmente os de multicamadas (SBM), que aparecem como solução para materiais destinados a suportar impactos balísticos de munição com alta energia cinética, como a 7,62 × 51 $\mathrm{mm}$ [2].

Os SBM's apresentam, de uma maneira geral, uma camada frontal responsável por quebrar ou fragmentar a ponta do projétil, além de absorver parte da energia cinética (requisito de alta dureza, exemplo cerâmico); uma camada intermediária, projetada para absorver o restante da energia cinética por deformação plástica, retendo o projétil (comumente, um polímero termoplástico); e uma terceira camada, com o objetivo de reter os fragmentos do projétil, bem como fragmentos da primeira camada do compósito (um metal, geralmente, alumínio) [3].

Com relação à camada intermediária, os tecidos produzidos com fibras de poliamida aromática e/ou polietileno de ultra alto peso molecular são atualmente muito empregadas, cuja finalidade é de absorver a energia cinética, resistindo a ação de penetração do projétil no alvo.

Considerando o Brasil, um país com forte potencial de cultivo e extração de lignocelulósicas, como o curauá, sisal, rami, coco, juta e outros, o desenvolvimento de compósitos balísticos híbridos, isto é, usando as tradicionais fibras sintéticas, já conhecidas, em conjunto com tecidos fabricados com tais lignocelulósicas, tem se tornado uma fonte inesgotável de pesquisa, visando à produção de compósitos sustentáveis.

A análise do comportamento balístico de compósitos laminados apresenta várias dificuldades devido à complexidade dos mecanismos envolvidos, tais como as tensões interlamelares ocorridas devido ao desajuste das propriedades das camadas adjacentes do compósito.

O desempenho balístico assim como o modo de falha dos compósitos reforçados por tecidos são influenciados pelas propriedades das fibras deste tecido bem como pelas propriedades da matriz. Adicionalmente, desde que a interface possua um papel prioritário na transferência da energia de impacto ao reforço, a tensão superficial entre as camadas tem um efeito significativo na absorção da energia cinética do projétil. A figura 1 apresenta os mecanismos de falhas para um compósito balístico reforçado por fibras/tecidos.

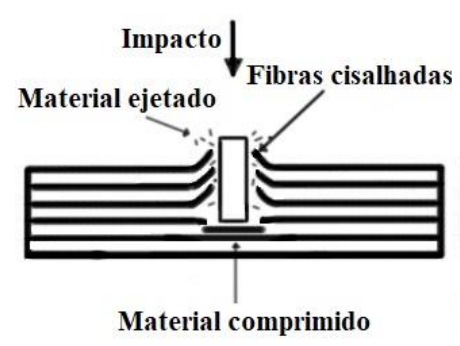

(a)

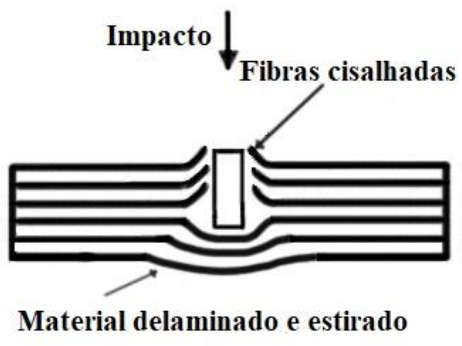

(b)

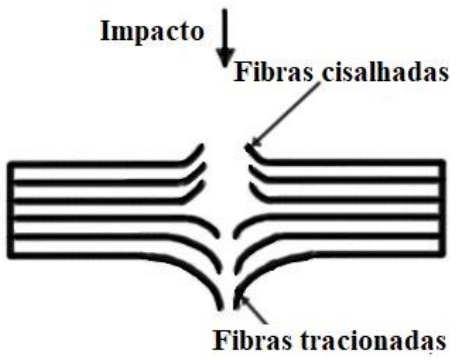

(c) 
Figura 1. Comportamento balístico dos compósitos reforçados por fibras/tecidos após impacto: (a) penetração parcial (primeiro estágio); (b) penetração parcial (segundo estágio); (c) penetração completa.

A penetração parcial ocorre em dois estágios: o impacto produz inicialmente, a compressão das fibras, induzindo a quebra das mesmas por cisalhamento (Figura 1a); quando a energia de impacto é absorvida e a velocidade do projétil diminuída, ocorre o estiramento da fibra e a delaminação entre as camadas (Figura 1b). A penetração completa produz a quebra das fibras, decrescendo a velocidade do projétil devido à absorção da energia cinética, seguido pela deformação plástica das mesmas, mostrando desta forma que este tipo de falha é controlado pela tensão de ruptura das fibras (Figura 1c).

Desta forma, este trabalho teve como objetivo produzir um compósito híbrido laminado, constituído de uma matriz polimérica, resina de poliéster, reforçada por manta de curauá e tecido de poliaramida (PCT) e avaliar o tipo de falha ocorrida após o ensaio balístico.

\section{MATERIAIS E MÉTODOS}

Os compósitos híbridos PCT fabricados, foram produzidos respectivamente na proporção de 60,4\% de poliéster, 33,2\% de manta de curauá e 6,4\% de Twaron em peso. As mantas de Curauá foram fornecidas pela empresa Pematec Triangel do Brasil Ltda, localizada na cidade de Santarém (PA). Quanto ao tecido de poliaramida e a resina poliéster cristal, estas foram fornecidas pelas respectivas empresas: Teijin Aramid e Resinpoxy Ltda.

A preparação dos compósitos baseou-se na literatura [4], na qual, a resina de poliéster foi misturada ao catalisador (peróxido metil-cetona) na proporção de $2 \%$ em peso, bem como, as mantas de curauá foram prensadas separadamente para uma melhor acomodação na matriz, além de secas em estufa a $60^{\circ} \mathrm{C}$ por $24 \mathrm{~h}$.

Em uma matriz metálica, fez-se a prensagem uniaxial da resina com as mantas de Curauá e tecidos de poliaramida, sob carga de 5 toneladas em uma prensa hidráulica de marca SKAY-15 ton. O sistema foi mantido sob pressão, em temperatura ambiente, e a desmoldagem do compósito foi realizada após um período de $24 \mathrm{~h}$ para que a cura do polímero fosse realizada. Uma perda de massa da resina foi considerada no processo de prensagem, devido ao vazamento da mesma na matriz.

Os compósitos PCT produzidos são retangulares com dimensões médias de $120 \mathrm{x}$ $150 \times 12,0 \mathrm{~mm}$ de espessura (Figura 2), com proporções em volumes de $39,54 \%$ e $4,87 \%$ de curauá e Twaron respectivamente.

A figura 2 apresenta a disposição esquemática dos reforços na matriz. 


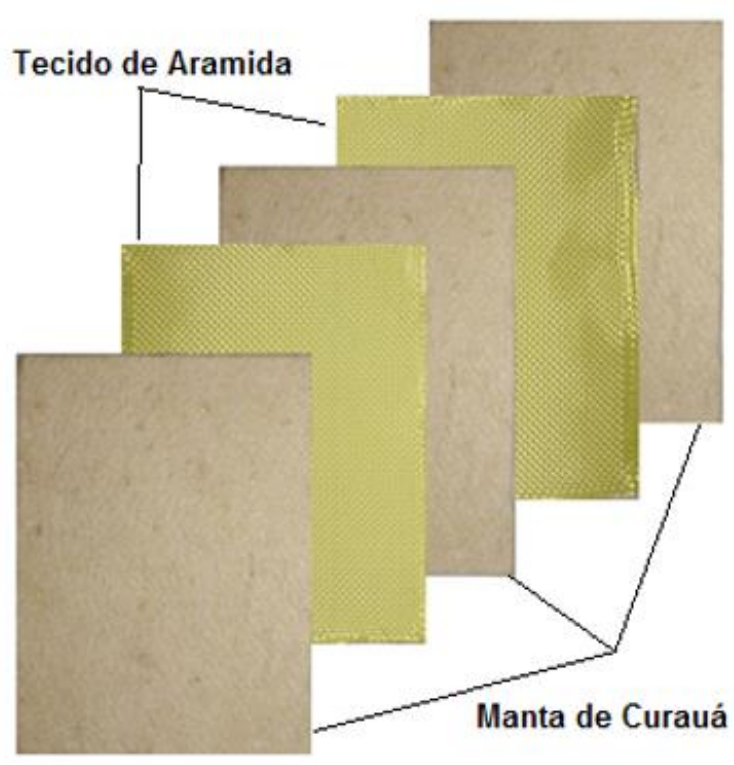

(a)

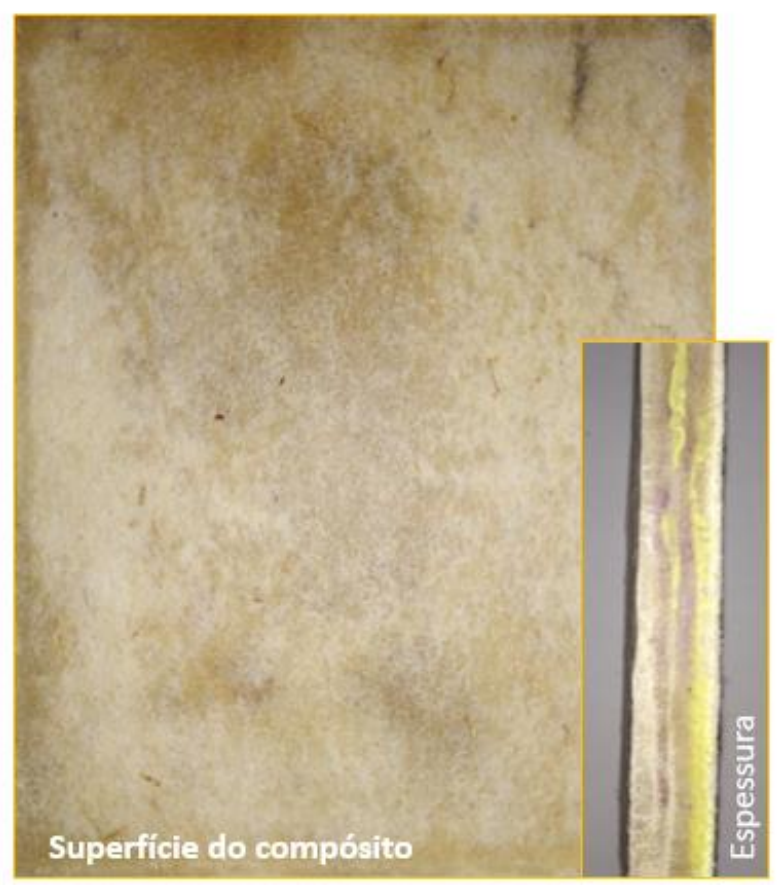

(b)

Figura 2. (a) Representação esquemática da disposição dos reforços na matriz; (b) Imagem frontal e lateral da placa do compósito híbrido PCT obtida.

O ensaio balístico foi realizado segundo a norma NIJ Standard 0108.01 [5] no Centro de Avaliações do Exército.

Foram utilizados projéteis com massa de $9,7 \mathrm{~g}$, da munição calibre $7,62 \times 51 \mathrm{~mm}$ fornecida comercialmente ao Exército. Os compósitos foram presos a um suporte metálico, através de grampos, a 15 (quinze) metros de distância do provete, com o objetivo de mantê-los perpendicularmente a trajetória do projétil, segundo a norma ABNT NBR 15000 [6].

Foi efetuado um disparo em cada compósito, sendo utilizados para avaliação balística 3 (três) compósitos. A velocidade dos projéteis no impacto e logo após a perfuração do compósito (velocidade residual) foi medida por meio do Radar Doppler. O cálculo da energia impacto $\left(E_{s}\right)$ e da energia residual $\left(E_{R}\right)$ foi calculado por meio da equação da energia cinética (Equação 1).

$$
\mathrm{E}=\frac{1}{2} \cdot \boldsymbol{m} \cdot\left(V^{2}\right)
$$

onde, $m$ é a massa do projétil e Vé a velocidade do mesmo.

Os valores de energia absorvida foram calculados por meio da Equação 2.

$$
E_{L}=E_{s}-E_{R}
$$

onde, EL é a energia absorvida pelo compósito.

Os valores da velocidade limite $\left(V_{L}\right)$ da blindagem laminada, foi estimada com o uso da Equação 3. 


$$
\mathrm{V}_{\mathrm{L}}=\sqrt{\frac{2 \cdot \mathrm{EL}}{m}}
$$

Após os ensaios balísticos, os compósitos foram submetidos à avaliação no microscópio eletrônico de varredura (MEV), afim de identificar os mecanismos de falha da blindagem laminada.

\section{RESULTADOS E DISCUSSÃO}

A Tabela 1 apresenta os valores obtidos e calculados para cada compósito ensaiado.

Tabela 1. Valores de $V_{S}, V_{R}, V_{L}, E_{S}, E_{R}, E_{L} e \% E_{L}$ do sistema de blindagem poliéster-aramidacurauá.

\begin{tabular}{cccccccc}
$\begin{array}{c}\text { CORPOS DE } \\
\text { PROVA }\end{array}$ & \multicolumn{7}{c}{ CARACTERÍSTICAS } \\
\cline { 2 - 8 } & $V_{S}(\mathbf{m} / \mathbf{s})$ & $V_{R}(\mathbf{m} / \mathbf{s})$ & $V_{L}(\mathbf{m} / \mathbf{s})$ & $E_{S}(K J)$ & $E_{R}(K J)$ & $E_{L}(\mathbf{J})$ & $\% E_{L}$ \\
\hline $\mathbf{0 1}$ & 849,526 & 803,479 & 363,02 & 3,50 & 3,13 & 369,16 & 10,55 \\
\hline $\mathbf{0 2}$ & 833,456 & 803,028 & 223,15 & 3,37 & 3,13 & 241,51 & 7,72 \\
\hline $\mathbf{0 3}$ & 857,509 & 814,419 & 268,41 & 3,57 & 3,22 & 349,41 & 10,86 \\
\hline Média & 846,830 & 806,975 & 284,86 & 3,48 & 3,16 & 320,03 & 9,71 \\
\hline
\end{tabular}

Observa-se que os valores de $\mathrm{E}_{\mathrm{L}}$ e o percentual da energia absorvida (\% $\left.\mathrm{E} \mathrm{L}\right)$ dos compósitos 1 (um) e 3 (três) foram da mesma ordem de grandeza, enquanto que 0 compósito 2 (dois), apresentou valores mais baixos. Esta variação pode ser atribuída a anisotropia do material, bem como, a formação de possíveis microfissuras nas interfaces dos constituintes durante a confecção dos compósitos, consequência da distribuição e interação dos reforços com a matriz [7].

Outro fator que possivelmente influenciou na variação dos resultados do compósito 2 em relação aos demais, foi a baixa velocidade de impacto obtida neste ensaio, o que pode ter alterado o comportamento do compósito quanto ao mecanismo de ruptura das fibras envolvidas.

A Figura 3 apresenta os impactos balísticos na face frontal e distal dos corpos de prova ensaiados. Observa-se que o compósito absorve a energia de impacto através do abaulamento e ruptura das fibras, porém sem apresentar aparente delaminação das camadas. 

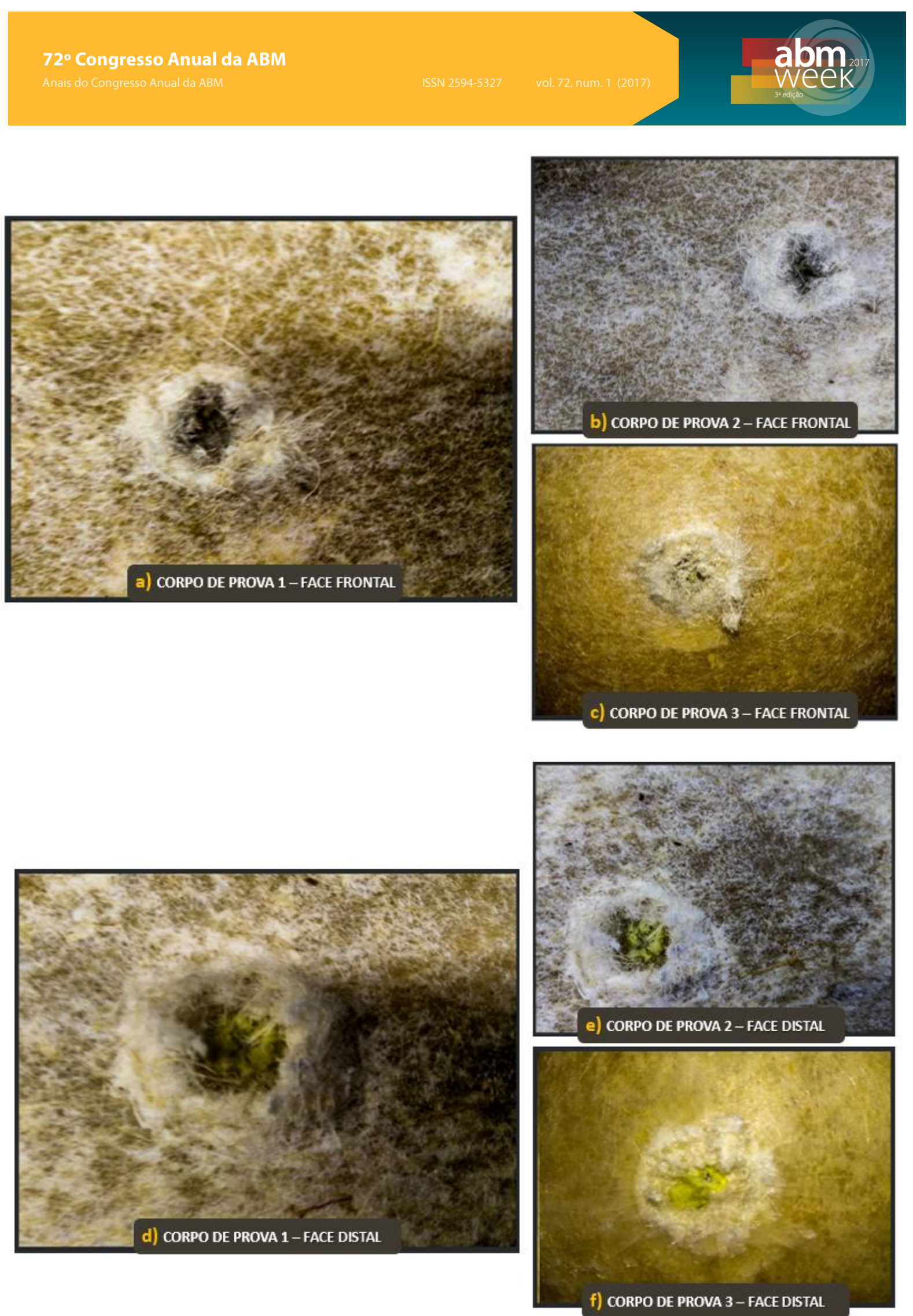

Figura 3. Impactos balísticos nas faces frontais e distais dos compósitos ensaiados.

Pode também ser observado que os impactos na face frontal dos compósitos (Figura $3 \mathrm{a}, \mathrm{b}, \mathrm{c}$ ) apresentam a mesma aparência com furos irregulares com "tufos" menores de fibras rompidas, enquanto a saída do projétil na face distal dos compósitos (Figura $3 \mathrm{~d}, \mathrm{e}, \mathrm{f}$ ) apresentaram "tufos" maiores de fibras rompidas como previsto no modelo 
proposto do mecanismo de falha para este tipo de compósito em impactos com penetração total (Figura1).

A formação de tais tufos pode ser explicada pela propagação de uma onda de tensão longitudinal, que percorre o eixo das fibras na velocidade do som do material, estirando os fios enquanto uma deflexão transversal ocorre, acarretando o desenvolvimento de tensão de tração na fibra que se propagam radialmente à uma distância do ponto de contato. No estágio final do impacto, o grau de deflexão da fibra aumenta e o tecido, que não se encontrará mais horizontalmente, apresentará um componente de tração na direção de impacto que desacelera o projetil. Nesse caso, todo o material atrás da frente da onda é igualmente tensionado, absorvendo assim, a energia do impacto. No entanto, a interação das ondas de tensão longitudinal e transversal resulta no aumento da taxa de deformação local, "cônica" em sua superfície [8]; [9].

Observa-se também, na superfície distal do compósito 3 (Figura 3 f)) trincas radiais em torno da fratura, sugerindo que um dos mecanismos de fratura do material foi por falha intralaminar. Esse tipo de falha sugere que após o impacto, trincas possam ser geradas na matriz do compósito, mas com arranjos difíceis de serem previstos. Caso essas trincas sejam pequenas, elas não contribuirão significativamente para a redução da absorção da energia de impacto do compósito laminado, mas possivelmente essas trincas serão iniciadoras de falhas interlaminares [10]; [11].

A Figura 4 apresenta, por microscopia eletrônica de varredura, a superfície da cratera produzida pelo impacto balístico no compósito 1, onde pode ser observado a ocorrência de falha intralaminar no material.

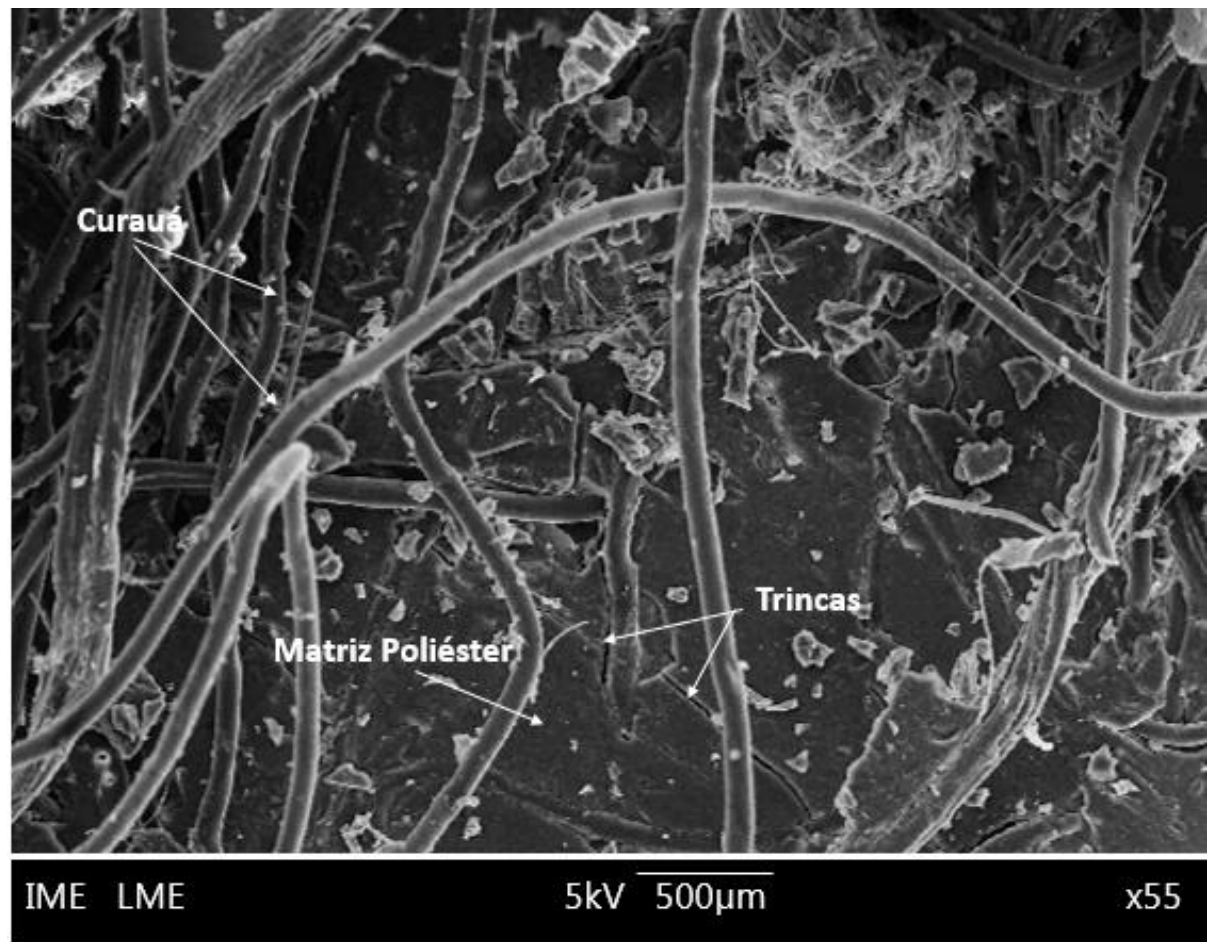

Figura 4. Aspectos de falhas intralaminares na superfície do compósito; 55x de aumento.

Observa-se também que a matriz poliéster exibe características que evidenciam o mecanismo de fratura frágil do material, pois ela apresenta superfície aparentemente lisa e trincas em várias regiões do compósito [12]. 
A Figura 5 apresenta aspectos gerais da cratera produzida pelo impacto balístico no compósito 1.

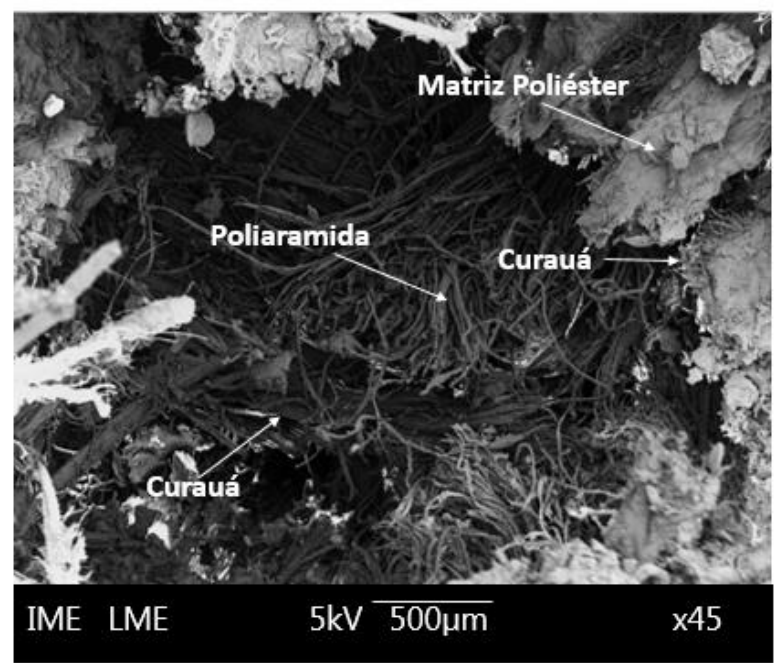

(a)

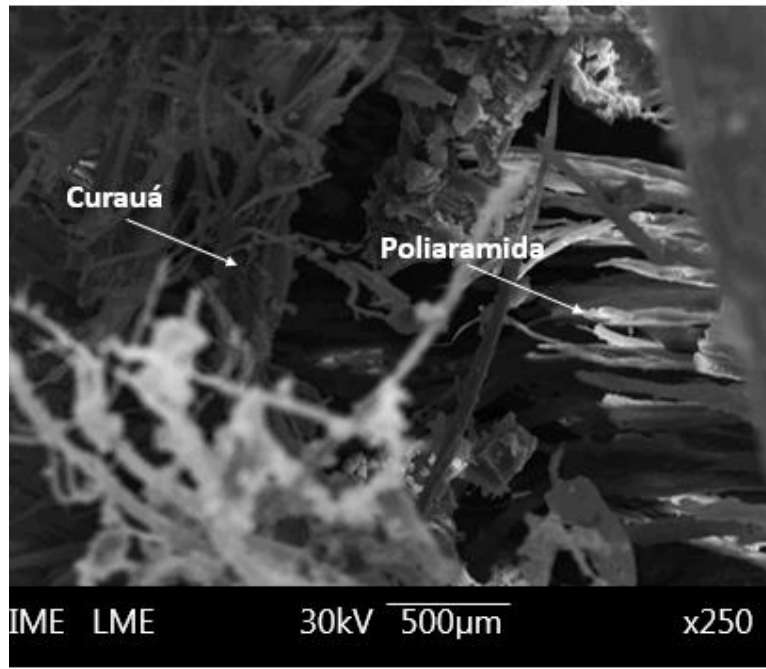

(c)

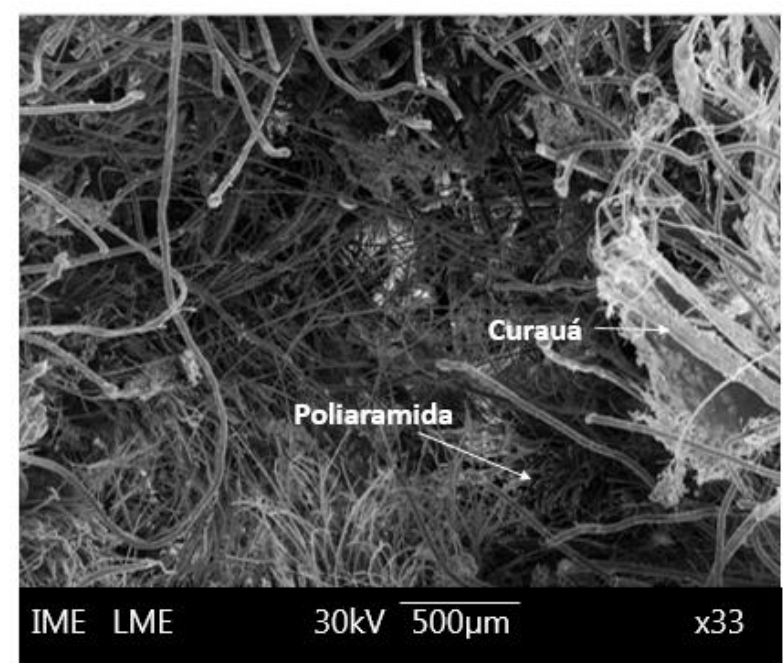

(b)

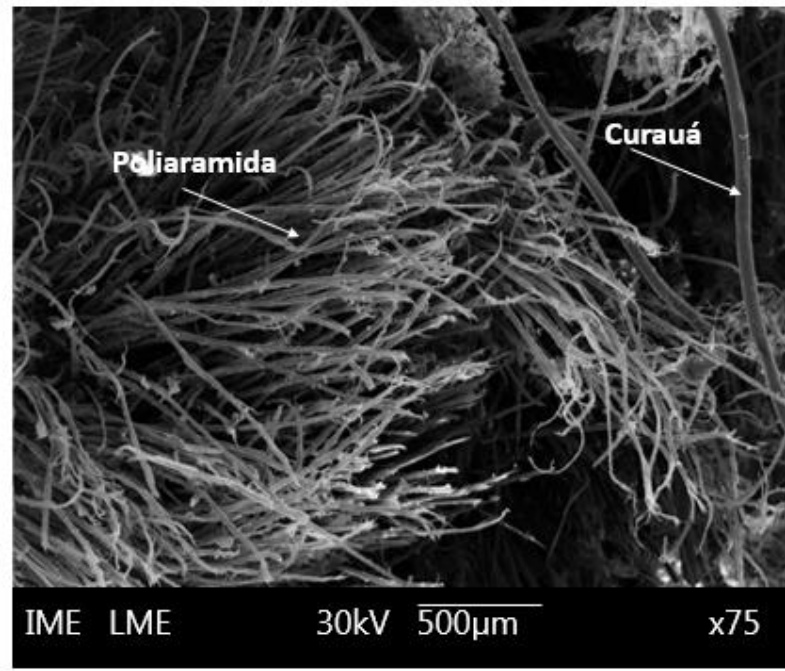

(d)

Figura 5. Aspectos geral da ruptura do compósito após ensaio balístico. (a) Fratura da Face Frontal do compósito; (b) Fratura da Face Distal do compósito; (c) x 250 da fratura da Face Frontal; (d) x 75 da fratura da Face Distal.

Pode-se observar na Figura 5a) e 5b) que o compósito sofreu uma pequena delaminação das interfaces, provenientes de falhas interlaminares, causadas por componentes de tensão fora do plano [11]. Caso essa delaminação fosse acentuada, demonstraria ser a interface fibra/matriz fraca, diminuindo assim a transferência do esforço ao reforço (tecido).

Esta pequena delaminação observada indica uma absorção da energia de impacto por meio da friç̧ão interlaminar entre as fibras do material, sem, contudo, prejudicar a eficiência do reforço. Isso ocorre porque o entrelaçamento das fibras no tecido teve grande influência na absorção da energia do impacto, pois os nós, regiões de encontro das fibras, agiram como pontos de reflexão e de divergência das ondas de deformação, dividindo a energia de impacto entre as fibras da trama (transversais) e do urdume (ortogonais) [13]. 
As figuras 5c) e 5d) mostram as fibras de poliaramida rompidas com leve estiramentos em suas pontas (microfibras), confirmando o fato de que a deformação plástica das fibras e a tensão de ruptura das mesmas, controlam esse tipo de falha no material, que segundo Silva e colaboradores [14] é atribuída a um complexo mecanismo de interação entre as microfibras e a matriz polimérica durante a propagação da trinca.

\section{CONCLUSÃO}

Os resultados mostraram que o mecanismo de falha macroscópico de perfuração do compósito estudado segue o mecanismo proposto, onde a quebra das fibras, tanto do tecido de poliaramida como da manta de curauá, ocorre de maneira análoga, produzindo menores "tufos" de fibras na face frontal e maiores "tufos" de fibras na face distal dos compósitos.

Os resultados ainda mostram que o mecanismo de falha microscópico aponta para microdelaminações nas interfaces matriz/tecidos (deslocamento das fibras) e falhas intralamelares (trincas na matriz) proporcionando uma maior dissipação da energia cinética de impacto.

\section{Agradecimentos}

Os autores agradecem ao Laboratório de Microscopia Eletrônica (IME) e ao Centro de Avalições do Exército (Caex) pela execução dos ensaios balísticos, e à Coordenação de Aperfeiçoamento de Pessoal de Nível Superior (CAPES) pelo apoio financeiro.

\section{REFERÊNCIAS}

1 Chawla, K. K. Composite materials: Science and engineering -2 ed. Springer. Verlag. 1998.

2 Braga, F.O., Bolzan, L.T., Lima, E.P., Monteiro, S.N. Desempenho de compósitos poliéster reforçados com fibras de curauá sob impacto balísitico 7,62 mm como blindagem monolítica. 22ํㅡㄹ CBECiMat - Congresso Brasileiro de Engenharia e Ciência do Materiais. Natal - RN; 2016: 4362-4369.

3 Wagner, L. Introduction. In: Bhatnagar, A. Lightweight ballistic composites - Militar and low-enforcement applications. Boca Raton: editora CRC, p. 01-25, 2006.

4 Bhatnagar, A. Lightweight ballistic composites - Militar and low-enforcement applications. Boca Raton: Editora CRC, 2006.

5 NIJ 0101.08-01, Ballistic Resistant Protective Materials. U.S. Department of Justice/Office of Justice Programs - National Institute of Justice. Washington DC, 1985. ABNT NBR 15000. Blindagens para impactos balísticos - classificação e critérios de avaliação, 2005.

7 Agarwal, B.D., Broutman, L.J., Chandrashekhara, K. Analysis and performance of fiber composites. Wiley. 3 ed.; 2006: 562 p.

8 Shahkarami, A., Cepus, E., Vaziri, R. Material responses to ballistic impact. In: Bhatnagar, A. Lightweight ballistic composites - Militar and low-enforcement applications. Boca Raton: editora CRC, p. 01-25, 2006.

9 Bittencourt, G. A.; Suarez, J. C. M.; Weber, R. P. Efeito da radiação gama em blindagens balísticas compósitas de poliaramida. 2011, 175f. Dissertação (Mestrado em Ciência dos Materiais) - Instituto Militar de Engenharia, Rio de Janeiro, 2011.

10 Abrate, S. Impact on composite structures. 1 ed.; Cambridge: Cambridge University, 1998, 289p. 
11 Romariz, A. L. Dano em placas laminadas devido ao impacto a baixa velocidades. 2008, 165f. Dissertação (Mestrado em Engenharia Mecânica) - Escola Politécnica da Universidade de São Paulo, São Paulo, 2008.

12 Braga, F. O., Monteiro, S. N. Comportamento balístico de uma blindagem multicamada utilizando compósito poliéster-curauá como camada intermediária. 2015, $132 f$.

Dissertação (Mestrado em Ciência dos Materiais) - Instituto Militar de Engenharia, Rio de Janeiro, 2015.

13 Vivas, V., Suarez, J. C. M., Weber, R. P. Influência da degradação ambiental no comportamento mecânico e balístico de compósitos produzidos com fibra de polietileno de ultra alto peso molecular. 2013, 216f. Dissertação (Mestrado em Ciência dos Materiais) - Instituto Militar de Engenharia, Rio de Janeiro, 2013.

14 Silva, L. C., Louro, L. H. L., LIMA, E. S. Comportamento balístico de compósitos epóxi - fibra natural em blindagem multicamada. 2014, 137f. Tese (Doutorado em Ciência dos Materiais) - Instituto Militar de Engenharia, Rio de Janeiro, 2014. 